\title{
A PRODUÇÃO TURÍSTICA DAS CIDADES ATUAIS: IMAGENS E REPRESENTAÇÕES SIMBÓLICAS DE ESPAÇOS E LUGARES
}

\author{
THE PRODUCTION OF TOURIST SPACES IN CITIES: IMAGES \\ AND SYMBOLIC REPRESENTATIONS OF SPACES AND PLACES
}

Marcelo Antonio Sotratti

Prof. Dr. Adjunto do Departamento de Turismo do IGEOG - UERJ mar_sotratti@yahoo.com.br

\section{RESUMO}

Alicerçada por meio de um discurso ideológico que contribui com a fetichização de paisagens e partes do território, a produção dos lugares turísticos se apóia no imaginário criado pelos meios de comunicação contemporâneos, pelos modismos culturais, por critérios estéticos e principalmente por estratégias de mercado. A produção material desses espaços envolve duas ações que refletem a ideologia espacial que permeia esse processo: o reducionismo simbólico do espaço, impresso aos territórios, aos lugares e às paisagens e a seletividade espacial que envolve as estratégias locacionais sob o controle de grupos hegemônicos do mercado turístico. O presente artigo apresenta as bases conceituais que envolvem a produção dos lugares turísticos e discute exemplos de paisagens e fragmentos de territórios amplamente empregados pela promoção turística e pelo planejamento desta atividade.

Palavras-Chave: Ideologia ï Lugares Turísticos - Paisagens ï Promoção turística 


\begin{abstract}
Anchored by an ideological discourse that contributes to the fetishization of landscapes and parts of the territory, the production of tourist places relies on the imaginary created by contemporary media, the cultural fads, for primarily aesthetic criteria and marketing strategies. The production of space involves two actions that reflect the ideology that permeates this process: the symbolic reductionism of space, form to the territories, places and landscapes and spatial selectivity involving locational strategies under the hegemonic control of the tourist market. This paper presents the conceptual foundations that involve the production of the tourist spaces and discusses examples of fragments of landscapes and territories widely employed by the tourism promotion and planning of this activity.
\end{abstract}

Keywords: Ideology - Tourist Places - Landscapes ï Tourism Promotion

\title{
Introdução
}

Numa sociedade onde o tempo livre se incorporou de forma significativa no cotidiano das pessoas, a necessidade de deslocamentos em busca do lazer, do conhecimento de outras culturas, da proximidade com a natureza, da busca da eterna juventude e da beleza se incorporou no imaginário da sociedade urbana das grandes cidades. Esse imaginário, fomentado pelas propagandas turísticas de lugares paradisíacos ou adaptados às mais excêntricas necessidades dos turistas, se apegam a imagens criadas pelo mercado turístico global na tentativa de mercantilizar o tempo livre por meio da projeção de paisagens dotadas de representações simbólicas que alimentem esse imaginário ideal de consumo do tempo livre.

Segundo Luchiari (2004, p. 122), o tempo e as paisagens são transformados em bens de consumo e produtos turísticos mediante a mercantilização do tempo livre e das paisagens. Segundo a autora ño tempo é um produto perecível, o uso das paisagens fugaz, de modo que o produto vendido pelo turismo é altamente valorizado e deve propiciar eficiência na apropriação dos recursos e na otimização do tempoò. 
A mercantilização do tempo e das paisagens por intermédio da propaganda turística fortalece os princípios ideológicos do mercado turístico mundial em aumentar a venda de seus produtos $\ddot{i}$ pacotes, roteiros, serviços e destinos - e se baseia numa produção turística intensa de lugares que se adequem ao imaginário idealizado de lugar de férias e de descanso.

Segundo Silveira (2002, pp. 36), a produção de lugares turísticos é alicerçada através da elaboração de um discurso idealizado que contribui com a fetichização de paisagens e de partes do território. Segundo a autora, a produção de lugares turísticos apóia-se na criação de uma psicosfera moldada pela publicidade, pelos modismos culturais, por critérios estéticos e principalmente por estratégias de mercado.

A psicosfera, como define Santos (1997, pp. 203-204), ñum reino das idéias, crenças, paixões e lugar da produção de um sentido, que também faz parte desse meio ambiente, desse entorno da vida, fornecendo regras à racionalidade ou estimulando o imaginárioò, influencia a produção turística das cidades globais no sentido de adequar paisagens e espaços idealizados no imaginário do turismo globalizado.

As paisagens constituem-se, segundo Silveira (2002, p. 37), num domínio visível que lhes confere uma aptidão à produção turística. Esta aptidão paisagística ï termo empregado pela autora - é uma manifestação da psicosfera, uma vez que por meio do turismo a constituição material da paisagem clama por significados e representações simbólicas.

As paisagens turísticas são valorizadas permanentemente e diferentemente, uma vez que a publicidade, os modismos, as estratégias de mercados são alimentadas pela psicosfera num determinado momento histórico. A paisagem, compreendida aqui como objeto de apropriação da psicosfera, atrai para os lugares turísticos uma produção material composta de infraestrutura e recursos tecnológicos, tornando-se ñum produto da ciência e da tecnologia, com conteúdo informacional e ideológico, que é capitalisticamente comercializadoò (SILVEIRA, 2002, p. 37). 
Os parques temáticos, por exemplo, dotados de paisagens fantásticas e imaginárias são produtos diretos da psicosfera moldada pelo mercado turístico mundial e pela indústria cultural. Para se tornar um lugar turístico, os parques temáticos produzem complexos sistemas tecnológicos e organizacionais que visam proporcionar aos visitantes a experiência idealizada pela propaganda turística.

O lugar turístico apresenta dessa forma um conteúdo informacional e ideológico que é comercializado pelo mercado, desenhando o que Santos (1997, pp. 190-192) designa como os pontos do meio técnico-científico-informacional. Nesse sentido, o lugar turístico incentiva o consumo de paisagens idealizadas por um imaginário criado e difundido pela psicosfera e comercializa produtos tecnológicos que permitem a apropriação dessas paisagens (SILVEIRA, 2002, p.37).

A produção espacial dos lugares turísticos se torna um modelo ideológico de desenvolvimento e acúmulo de riquezas, impulsionados pela aptidão paisagística criada pela psicosfera. A valoração das paisagens segundo os significados determinados pela psicosfera antecede à chegada da tecnosfera, ou seja, do conjunto de objetos técnicos implantados nos lugares (SANTOS, 1997, p. 204), propiciando disputas entre instâncias governamentais e estimulando uma publicidade turística baseada em imagens idealizadas. (SILVEIRA, 2002, pp. 38-39)

A produção material dos lugares turísticos envolve, assim, duas ações que refletem a ideologia espacial que permeia esse processo de produção espacial: o reducionismo simbólico do espaço, impresso aos territórios, aos lugares e às paisagens e a seletividade espacial que envolve as estratégias locacionais sob o controle de grupos hegemônicos do mercado turístico, discutidos mais detalhadamente neste artigo.

\section{O reducionismo simbólico e a seletividade espacial na produção turística dos lugares}


Num cenário de alta competitividade entre os destinos turísticos mundiais, o apelo mercadológico dos países, cidades e lugares se apóia primeiramente na formação de uma imagem que atraia fluxos crescentes de turistas para tais destinos. Segundo Lohmann \& Palosso Neto (2008, p.347), a imagem tem se tornado um fator fundamental para o viajante no processo de escolha de um destino turístico. Segundo os autores, a competição cada vez mais crescente entre vários destinos evidencia a necessidade de um plano e de estratégias de marketing vinculadas à formação de uma imagem positiva e de alto poder de atratividade.

A formação da imagem turística dos lugares consiste numa fase importante do processo de produção turística dos lugares e se baseia na redução simbólica do espaço e do território a partir de uma idealização baseada no imaginário construído pelo mercado turístico.

Segundo a Associação Americana de Marketing ${ }^{1}$, a imagem consiste na percepção, na compreensão e na idéia que os consumidores possuem de determinado produto. Para o marketing turístico, a imagem de um lugar pode ser definida como um conjunto de atributos formado por crenças, idéias e impressões que as pessoas têm sobre determinado local (KOTLER, P. et al., 2006, pp.182-183). Segundo o autor, as imagens costumam representar a simplificação de inúmeras associações e fragmentos de informações e são produtos mentais que sintetizam múltiplas informações e impressões de determinados destinos.

Para Gastal (2005, p. 23), a publicidade turística tem nas imagens sua forte aliada na conquista de consumidores. Segundo a autora, as imagens são escolhidas deliberadamente de forma a conduzir o olhar do turista e transmitir determinados sentimentos a eles. As imagens turísticas podem levar o consumidor a conhecer determinados produtos ou mesmo somar outros valores às imagens pré-existentes no imaginário do turista sobre determinado lugar, advindos da literatura, do cinema ou de outros veículos midiáticos.

Nesse sentido, observa-se que a criação de imagens de lugares turísticos se baseia no reducionismo simbólico do território para fortalecer o imaginário dos turistas 
potenciais. O reducionismo simbólico aqui discutido está associado ao conceito de redução narrativa desenvolvido por Berdoulay (2009, pp. 18-19), onde o planejamento e a promoção turística reduzem a complexidade e diversidade histórica, social e cultural dos lugares a imagens estereotipadas e distorcidas para atrair públicos crescentes a tais lugares.

Tal reducionismo simbólico ocorre ao se associar algumas paisagens à totalidade através de uma representação simbólica intencionalmente criada pelo marketing turístico, praticado pelo Estado ou pelo mercado. Esse reducionismo se baseia principalmente nos ideais impostos pela lógica global do turismo, distorcendo significativamente a dinâmica espacial local e criando imagens equivocadas da realidade ambiental, social e cultural dos destinos. Algumas situações podem ser observadas nas imagens a seguir.

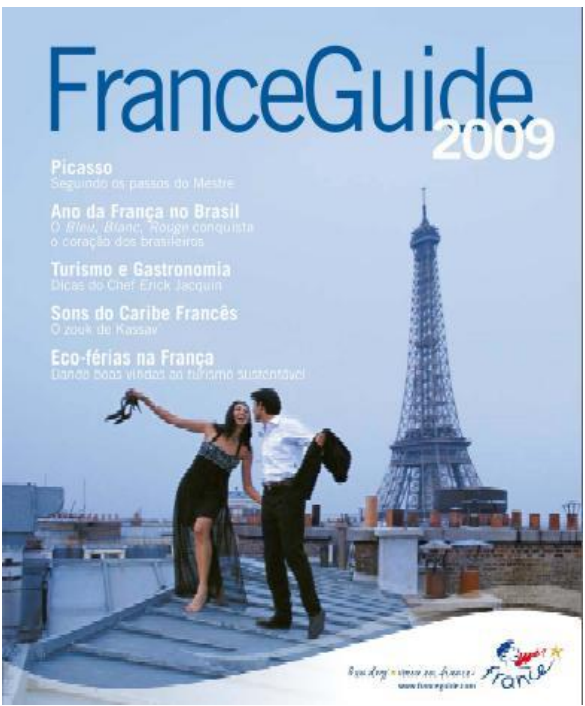

Figura 1 - Material Promocional da Maison de La France ï Órgão Oficial de Promoção Turística do Governo Francês. Fonte: Maison de La France, http://br.franceguide.com, 2010

Observa-se a partir da imagem acima $̈$ figura 1 - que o material promocional da Maison de La France ï agência de promoção turística francesa para o mercado internacional $i ̈$ possui uma tendência constante de reduzir o território francês à capital Paris, desconsiderando cidades e regiões de grande importância econômica, cultural ou 
mesmo turística do território. Da mesma forma, as imagens de Paris normalmente estão associadas a paisagens que possuem a presença da Torre Eiffel, importante marco paisagístico da capital francesa. Essa associação, além de reduzir a grandiosidade e a beleza da paisagem urbana de diversos bairros da cidade, promoveu uma associação equivocada entre a construção e presença da Torre Eiffel com a sociedade francesa.

Embora o marketing e a propaganda turística tenham conseguido incorporar esse importante objeto no imaginário dos moradores parisienses e franceses como um patrimônio cultural francês, sua história demonstra uma dissociação clara entre a memória da cidade e do país e a presença da torre. Segundo o site oficial da Torre Eiffel $^{2}$, a torre tornou-se o símbolo mais proeminente de Paris e da França. A torre é uma parte do cenário caracterizado em dezenas de filmes que se passam em Paris. Seu estatuto de ícone é tão determinado que ainda serve como um símbolo para toda a nação da França, como quando ela foi usada como o logotipo da candidatura francesa para sediar os Jogos Olímpicos de Verão de 1992.

Outros exemplos significativos de reducionismo simbólico do território podem ser observados nas imagens empregadas pelos órgãos de promoção turística australiano e egípcio, ilustradas a seguir.

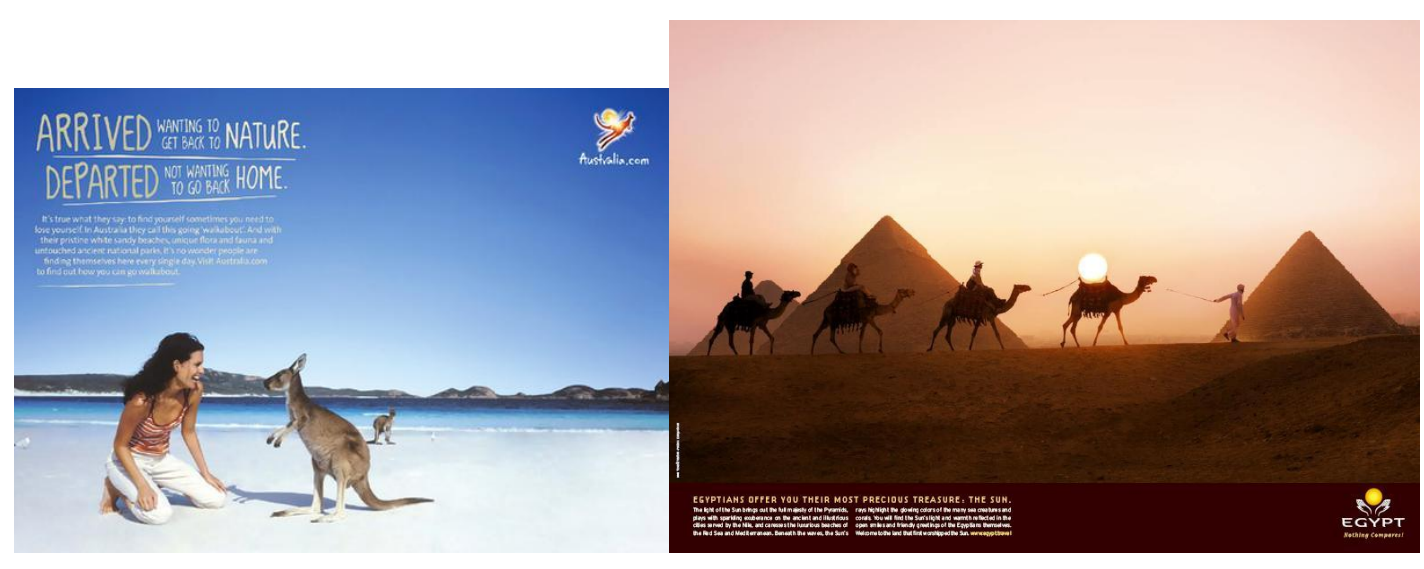

Figuras 2 e 3. Peças publicitárias do Tourism Australia e do Tour Egypt, órgãos de promoção turística da Austrália e do Egito respectivamente. Fonte: http://www.tourism.australia.com, http://www.touregypt.net , 2010 
Observa-se pela primeira imagem acima a associação permanente da Austrália com o mamífero que virou símbolo do país ï o canguru. De acordo com a propaganda turística, o animal está presente em todo o espaço australiano e integra as mais diferentes paisagens, como praias, cidades, desertos e complexos esportivos. Da mesma forma, o Egito é reduzido a uma paisagem que retrata um patrimônio material de um passado distante e glorioso $\ddot{i}$ o império dos faraós $\ddot{i}$ e a princípios religiosos completamente distantes da realidade urbana, cultural e religiosa da cidade onde está inserida, no caso Cairo.

O Brasil como um destino internacional emergente no mercado turístico também se utiliza do reducionismo simbólico para incentivar o aumento do fluxo de turistas ao território brasileiro. Nesse sentido, a associação do Brasil com a cidade Rio de Janeiro é antiga e expressa diferentes expressões ideológicas do órgão responsável pela promoção turística internacional Ï a EMBRATUR durante as últimas décadas.

Nos anos 70, a propaganda turística brasileira apresentava grande apelo sexual, explorando imagens da mulher carioca com poucas roupas em paisagens normalmente associadas ao prazer, como praias e desfiles de escolas de samba. (ALFONSO, 2006, p.89). Essa imagem reforçava o imaginário do consumidor turístico da época de um Brasil hedonista e de sexo fácil, que já era influenciado pela música da Bossa Nova de Tom Jobim ï Garota de Ipanema e pelas imagens do carnaval carioca difundidas pelas redes de televisão internacional. Isso resultou na produção de um lugar turístico carioca baseado na exploração sexual de mulheres e adolescentes, acentuando os conflitos sociais e econômicos da capital fluminense (Figuras 4 e 5). 


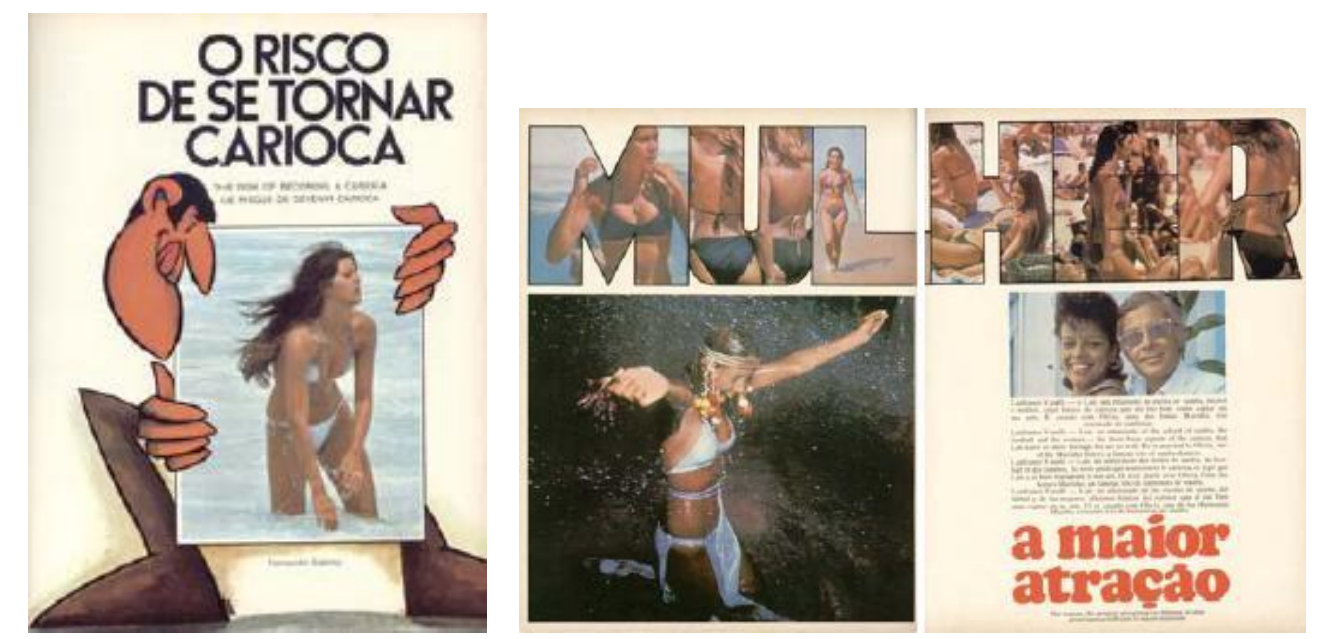

Figuras 4 e 5. Revista Rio, Samba e Carnaval, distribuída na década de 70 do séc. XX no Brasil e no exterior com o apoio da EMBRATUR. Observa-se o uso da imagem da mulher como o principal atrativo turístico do Rio de Janeiro.

Fonte: EMBRATUR (1973-1975 apud Alfonso, 2006, pp. 88-89.

Nos últimos anos, a própria EMBRATUR se empenhou em alterar a imagem do Rio de Janeiro e do Brasil e reforçou imagens que valorizam paisagens de alto valor cênico e que podem se visitadas e apreciadas por toda a família (Figura 6) e processou guias turísticos que reforçaram o imaginário do Rio de Janeiro como destino sexual. O guia turístico ñRio for Partiersò causou polêmica ao classificar as mulheres cariocas em categorias segundo sua disponibilidade e interesse em realizar atos sexuais com turistas estrangeiros. Embora o guia não faça referência direta à prostituição, a Embratur argumentou à Justiça que a classificação e a indicação de locais para o turista buscar sexo viola a dignidade humana. De acordo com a EMBRATUR, o foco da promoção turística do Brasil no exterior é a diversidade cultural do país e suas belezas naturais. De acordo com a entidade,

ño Ministério do Turismo condena qualquer utilização de imagens, expressões ou apelos que remetam à exploração do turismo com conotação sexual e, por este motivo, não faz cessão de uso da Marca Brasil para publicações que vão de encontro a este conceito (EMBRATUR, 2009) ${ }^{3}$. 


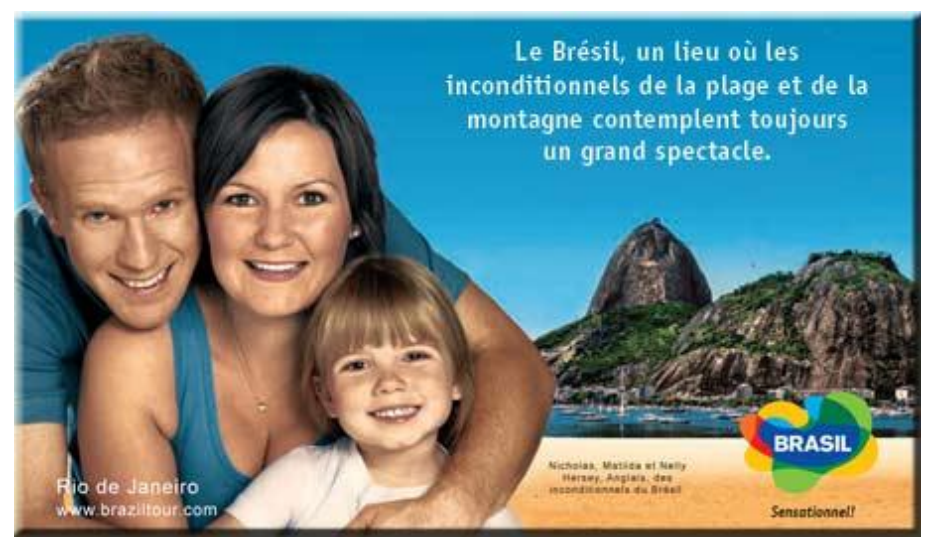

Figura 6 - Peça publicitária da Campanha Brasil: Vire Fã, veiculada pela EMBRATUR entre 2004 e 2008. Fonte: EMBRATUR, disponível em: http://www.brasilnetwork.tur.br, 2010.

O reducionismo simbólico do território assume atualmente proporções mais drásticas em função das exigências mercadológicas e competitivas do turismo globalizado. Os lugares turísticos, segundo as premissas do marketing contemporâneo, devem possuir, além de uma imagem positiva consolidada no imaginário dos turistas potenciais, uma marca que exprima a identidade e a qualidade dos destinos. Segundo Chias (2007, p.131), a marca turística se constitui num poderoso elemento de comunicação, uma vez que ela agrega valores identitários aos produtos turísticos de determinado território e fortalece o conteúdo de sua imagem e o posicionamento competitivo dos destinos no mercado turístico mundial.

A marca turística consiste, segundo o autor, num estandarte da promoção de um país no exterior e se transforma ñno motor do conhecimento externo do território e num símbolo de identidade aceito internacionalmenteò(CHIAS, 2007, p.133).

Essa afirmação nos faz refletir sobre o papel do Estado na promoção de seu território num mercado competitivo como o turismo. Reduzir o território a uma marca, talvez seja a demonstração mais clara de uma ideologia do Estado voltada aos interesses do capital globalizado, ao invés de reforçar seu papel no ordenamento e organização desse território. A redução simbólica propagada pelas marcas turísticas de territórios vem promover a homogeneização e a inserção de valores estereotipados aos lugares 
turísticos, distorcendo realidades espaciais, culturais e sociais que caracterizam esses territórios.

Os estereótipos espaciais normalmente empregados nas marcas turísticas são formados a partir do próprio processo de criação da marca. Segundo Chias (2007, pp.138-140), as marcas devem ser a expressão da identidade dos lugares, devendo possuir em primeiro lugar um nome, uma mensagem, um logotipo que traduza a essência e a identidade dos lugares. A metodologia se baseia, segundo o autor, numa série de entrevistas com turistas, lideranças governamentais e população local, seguida de um trabalho de desenho executado por uma agência publicitária. Observa-se que a criação de marcas turísticas reforça a produção de identidades estereotipadas baseadas em olhares técnicos e externos e muitas vezes alheios às impressões da sociedade local. Alguns desses resultados podem ser observados na imagem a seguir:
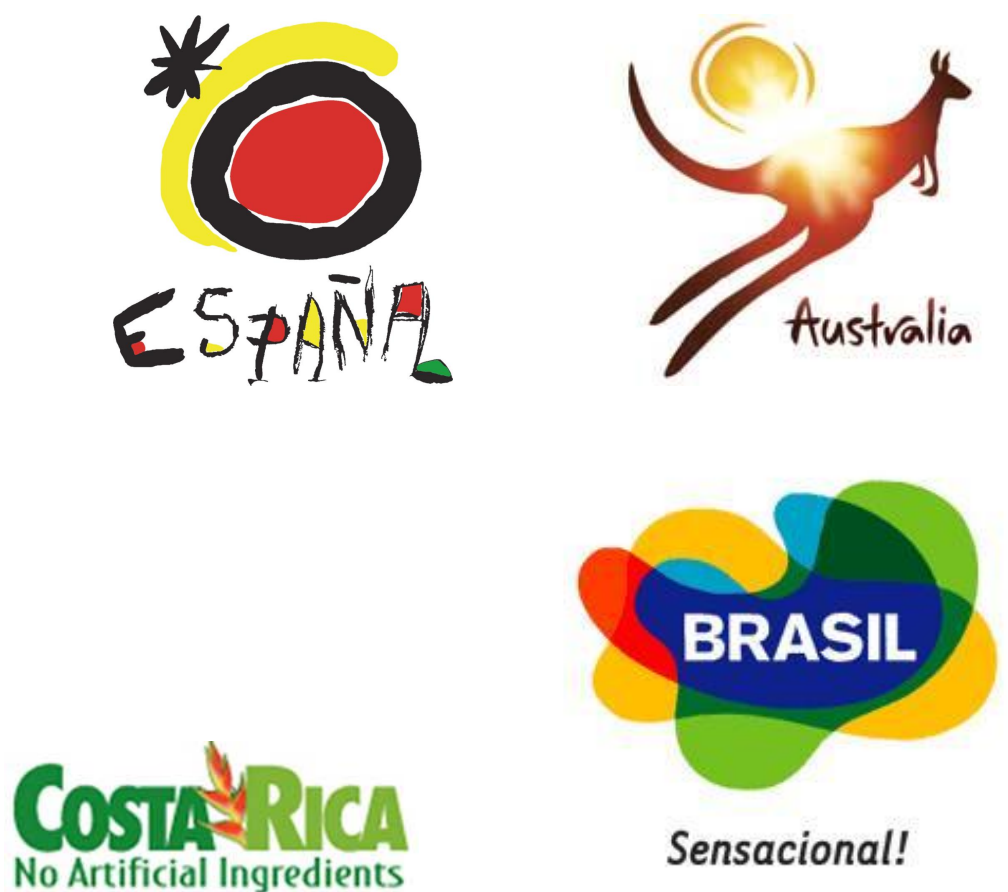

Figura 7 - Marcas Turísticas de alguns países inseridos no mercado turístico gens$\begin{array}{lll}\text { frases n } & \begin{array}{l}\text { internacional. Fonte: respectivos sites dos órgãos promocionais de } \\ \text { turismo:http://www.tourspain.es }\end{array} & \text { http://www.tourism.australia.com, além }\end{array}$ de refor http://www.visitcostarica.com, http://www.brasilnetwork.tur.br, 2010. influenciam sobremaneira a produção turística de regiões, cidades ou pequenos lugares. 
Uma análise comparativa entre as marcas expressas na Figura 8 pode auxiliar a constatação de estereótipos empregados pelo mercado turístico.

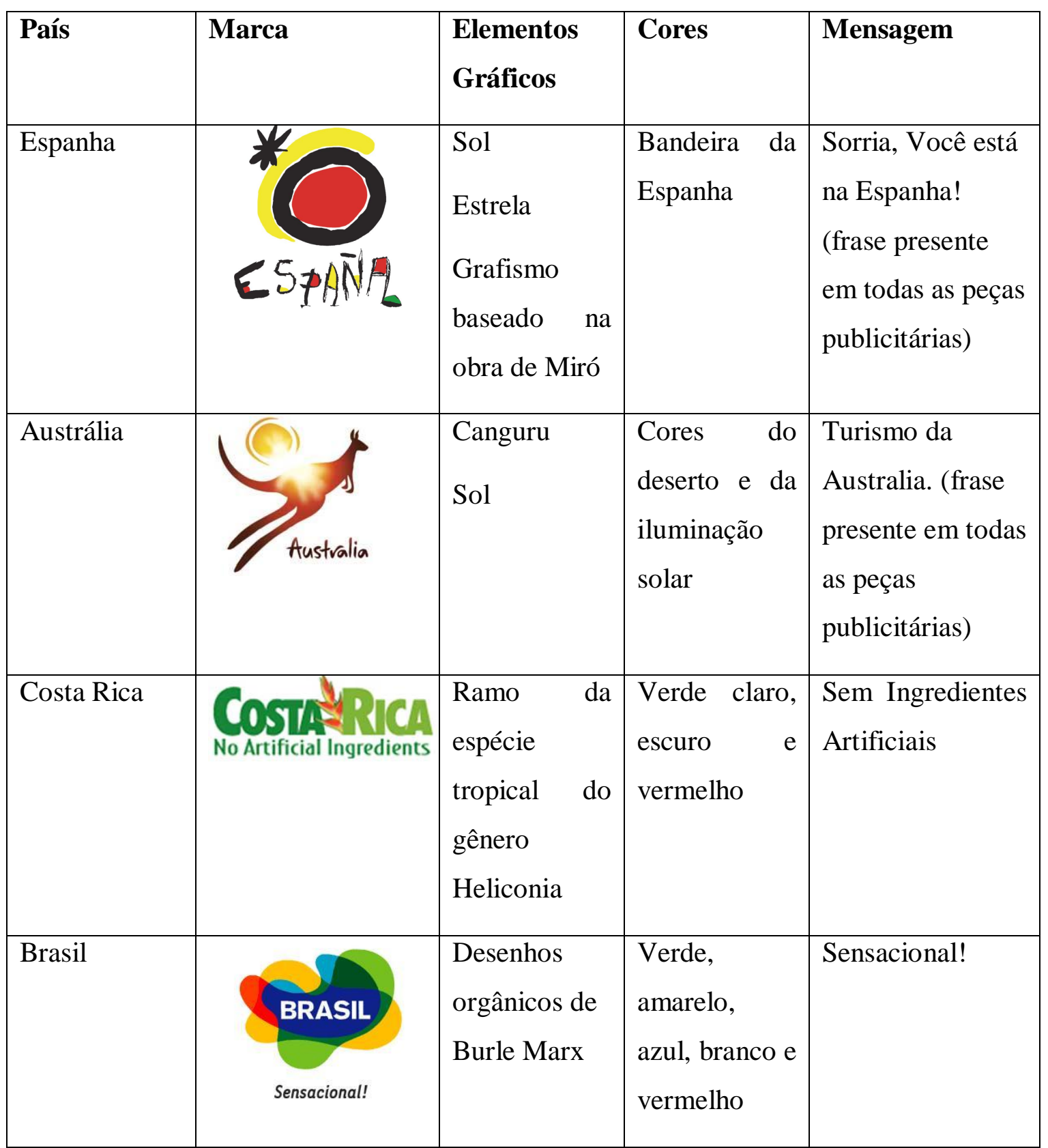

Figura 8 - Marcas turísticas de alguns países líderes no mercado emissivo internacional de turistas. Fonte: elaborado pelo autor a partir das marcas turísticas disponibilizadas nos sites oficiais de turismo dos respectivos países.

A figura acima mostra comparativamente o apelo simbólico do território empregado em tais marcas. O sol está presente de forma direta nas marcas espanhola e 
australiana e indireta $і ̈$ através da cor amarela $̈$ na marca Brasil. Essa presença reforça a associação do turismo com o verão, com o sol e com as praias e estimulou sobremaneira a produção turística extensiva das cidades costeiras de tais países.

No entanto, as alterações climáticas observadas em todo o planeta como chuvas constantes, invernos rigorosos e queimadas extensivas vem demonstrando a supremacia da força da natureza frente às modificações ambientais causadas pelo homem e pelo turismo, distanciando a realidade das expressões simbólicas presentes em tais marcas. É o caso da destruição causada pelas enchentes no litoral sul do Rio de Janeiro e em São Paulo na virada dos anos 2009 e 2010, do inverno rigoroso no continente europeu no mesmo período e da seca que provocou incêndios alarmantes na Austrália em 2009.

As marcas turísticas também se utilizam de alguns elementos específicos que caracterizam parcialmente a cultura de tais países. É o caso da marca turística da Espanha, que nitidamente se utiliza de um grafismo característico de Miró para compor seu logotipo. Cabe ressaltar que o processo de criação da marca Espanha está nitidamente associada ao processo de requalificação urbana da cidade de Barcelona durante o período dos Jogos Olímpicos de 92, elevando a capital catalã ao status de grande centro turístico espanhol e europeu. Observa-se nitidamente nesse caso, um reducionismo simbólico que valoriza, de forma subjetiva, regionalismos culturais e sociais.

No caso da Costa Rica e da Austrália, observa-se a utilização de elementos que caracterizam as áreas naturais de tais países ï o canguru e um ramo da espécie tropical do gênero Heliconia ï supervalorizando a presença de áreas naturais e o contato com a natureza em tais países, ignorando cidades expressivas presentes nesses territórios, sobretudo na Austrália.

Em relação à marca Brasil, observa-se a utilização de uma composição gráfica dificilmente percebida pelos turistas estrangeiros $і ̈$ inclusive talvez pela grande parte da população brasileira ï uma vez que utiliza formas orgânicas características da obra do renomado paisagística brasileiro Burle Marx. No entanto, as diversas cores utilizadas na 
marca brasileira reforçam a imagem de exoticidade do território brasileiro no imaginário do turista internacional.

É curioso notar que todas as marcas analisadas possuem frases de efeito que buscam despertar algumas sensações aos turistas em relação a tais países como alegria $\ddot{i}$ marca espanhola -, emoção ï marca brasileira ï e autenticidade ï marca costa-riquenha. Da mesma forma que os elementos gráficos, tais frases de efeitos supervalorizam aspectos relacionados à hospitalidade em tais países e reduzem significativamente a realidade sócio-espacial que envolve tais territórios. No caso da Austrália, observa-se que a marca se associa diretamente ao órgão de promoção do turismo australiano no exterior - Turismo da Austrália $і ̈$ indicando a valorização do Estado em relação ao desenvolvimento turístico no território.

Observa-se dessa forma, que a formação de imagens e a criação de marcas turísticas como elementos de atratividade estão diretamente associadas à psicosfera criada pelos grupos hegemônicos locais e mundiais, e se constituem em estratégias comumente empregadas pelos países como uma forma de inserção no mercado turístico globalizado.

A psicosfera, que alimenta a produção turística dos lugares, influencia as práticas de reducionismos simbólicos no território, selecionando e transformando espaços, supervalorizando paisagens e se constituindo num motor propulsor na implantação de equipamentos e infraestrutura destinadas ao lazer e consumo.

Observa-se ainda, que a aptidão paisagística dos lugares turísticos, defendida por Silveira (2002, p.37), implica normalmente numa seletividade espacial de determinadas porções do território que atendam aos valores simbólicos impressos pela psicosfera.

Praias, cachoeiras, monumentos, centros históricos, fazendas históricas são selecionados para atender aos desejos de consumo do mercado turístico mundial. Essa seletividade promove, assim como a formação de imagens e de marcas turísticas, uma redução simbólica do espaço e do território, uma vez que a intensa turistificação dessas 
áreas se projeta no mundo como a totalidade destes destinos, desprezando espaços significativos e vitais dos territórios.

Fruto de uma ideologia espacial a partir de uma relação entre finalidade e totalidade, como aponta Berdoulay (1985, pp.212, 213), a seletividade espacial dos lugares turísticos se materializa a partir de duas ações básicas: a concentração de infraestrutura turística e a apropriação de paisagens de alto valor simbólico.

Com a seleção de determinadas paisagens designadas pela psicosfera como elemento de consumo, o mercado turístico necessita agregar a esse elemento objetos reais e passíveis de mercantilização (SILVEIRA, 2002, p.37). Esses objetos se constituem em complexos sistemas de engenharia e de organizações que se traduzem no lugar turístico como infraestrutura turística.

Se analisarmos o exemplo das cidades litorâneas brasileiras, como algumas capitais nordestinas, observa-se nitidamente a seletividade espacial de alguns bairros costeiros para uma intensa e segregada produção turística. Segundo Silva \& Ferreira (2007, p. 110), o litoral nordestino foi inserido na lógica de consumo e de investimentos do mercado europeu, atraindo um volume de capital nacional e estrangeiro para a construção intensiva de equipamentos e de infraestrutura turística.

Segundo os autores, empresas portuguesas e espanholas são as maiores investidoras, evidenciando um fenômeno denominado pelos autores como transbordamento das atividades turísticas desenvolvidas no sul de Portugal e da Espanha. Esse fenômeno está transformando o ritmo de crescimento das cidades e o valor de troca dessas áreas, bem como a relação entre tais espaços e as áreas tradicionais de tais núcleos urbanos (SILVA \& FERREIRA, 2007, p 110).

O caso de Natal, capital do Rio Grande do Norte, é um exemplo significativo O bairro de Ponta Negra, tradicional praia dos natalenses até o final dos anos 80, passou por uma intensa transformação a partir da ação integrada das políticas públicas de desenvolvimento turístico e de investidores privados nos anos 90 do século XX. 
Com o Prodetur-NE ${ }^{4}$, o bairro foi dotado de boa acessibilidade ao aeroporto, ao centro da cidade e a outras praias do litoral sul da região metropolitana. Paralelamente, a Prefeitura criou em 2000 uma lei que favoreceu o adensamento e a verticalização do bairro, atraindo uma intensa atividade imobiliária nacional e internacional para a construção de resorts, pousadas, hotéis, flats, restaurantes e residências secundárias direcionadas ao mercado europeu (SILVA et al. 2006, pp. 144-146).

Hoje, o bairro encontra-se completamente ocupado por hotéis, restaurantes e casas noturnas e segregado dos outros bairros tradicionais da cidade, conforme pode ser observado na figura 9.

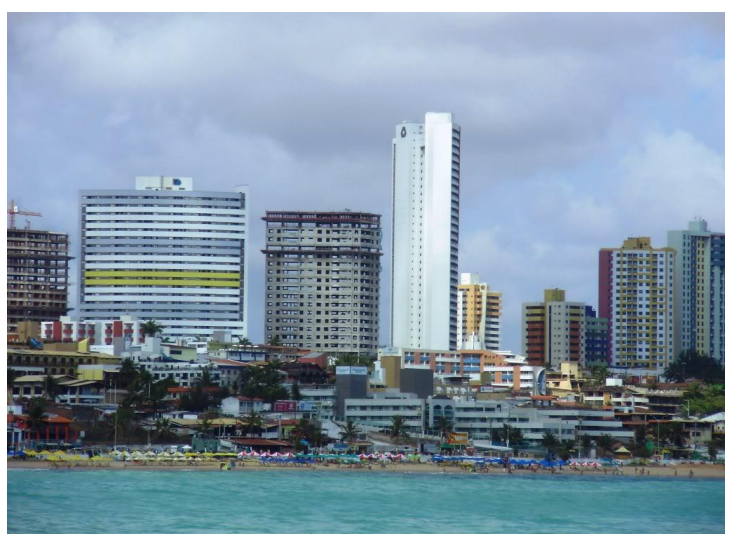

Figura 9 - Bairro de Ponta Negra, Natal, RN. Observa-se em primeiro plano, a intensa proliferação de barracas ao longo da praia. No plano intermediário, pousadas, pequenos hotéis e restaurantes e ao fundo intensa verticalização para residência secundária, normalmente direcionada ao público estrangeiro.

Fonte: Skycrapercity,. Foto de Manu Neto, 2009.

http://www.skyscrapercity.com/showthread.p $\underline{\mathrm{hp} ? \mathrm{t}=1018609}$

A seletividade espacial para a produção turística também ocorre a partir da apropriação de paisagens com alto valor simbólico. Algumas paisagens urbanas, como os centros históricos, são dotados de intenso valor simbólico para a cidade ou para o país devido a sua natureza histórica, estética ou mesmo afetiva. Tais áreas, normalmente objetos de preservação por parte dos órgãos estatais, acabam sendo excluídas do processo de reestruturação econômica das cidades e marginalizadas pela sociedade local devido a sua má conservação ou ocupação por grupos sociais indesejados.

No entanto, observa-se atualmente uma tendência de inserção e incorporação dessas formas pretérita na dinâmica econômica das cidades através de ações estratégicas e da resignificação de seus valores simbólicos. Denominadas por Santos como rugosidades (2002, pp. 173-174), essas formas passadas são reincorporadas ao espaço em transformação por meio da refuncionalização. 
A refuncionalização consiste no processo de transformação de funções dos objetos num determinado processo histórico. A refuncionalização é uma consequiência natural da própria reestruturação sócio-espacial de determinada cidade, liderada por alguns grupos sociais com intencionalidades específicas. A requalificação urbana, por exemplo - denominação associada a uma estratégia definida pelo modelo do planejamento estratégico ï está associada à refuncionalização de áreas dotadas de patrimônio, ou seja, de objetos antigos que permaneceram inalterados no processo de transformação do espaço urbano. Por meio de uma refuncionalização dirigida e estratégica, o emprego de funções vinculadas ao capitalismo global como turismo, cultura, negócios, comércio e residências é incentivado nessas ações de planejamento urbano (SASSEN \& ROOST, 2001, p. 72, BORJA, 2001, pp. 78-79, PORTAS, 1998, p. 53, SOTRATTI, 2005, pp 14-16).

Dessa forma, as intencionalidades envolvidas na requalificação implicarão em novas representações simbólicas das rugosidades existentes no espaço. Essa transformação poderá criar uma nova territorialidade no espaço urbano, externalizando uma ideologia espacial por critério de seletividade e produção turística.

Estas novas representações simbólicas são criadas a partir de uma psicosfera que coloca o patrimônio e a cultura como elementos de consumo, mediante uma pseudoatmosfera de valorização da memória. A partir da valorização do patrimônio como cenário estetizado, a refuncionalização adapta esses objetos a funções turísticas e os transforma em equipamentos como hotéis, bares, restaurantes. A paisagem cenarizada do patrimônio requalificado é valorizada pelo seu conjunto, através de representações simbólicas ligadas a seu valor histórico e estético, mas nitidamente percebe-se que essa significação acaba se reduzindo a um pano de fundo para o consumo turístico.

Individualmente, os edifícios curiosamente perdem seu significado de cenário ñantigoò e assumem sua importância como equipamentos turísticos. É o caso de antigos mosteiros localizados em centros históricos, que no conjunto requalificado são percebidos pelo seu conjunto estético e simbólico e individualmente são percebidos pelo seu valor econômico e mercantil, ou seja, como um meio de hospedagem sofisticado. 
O caso da requalificação urbana do centro Histórico de Salvador Pelourinho é um bom exemplo da seletividade espacial para produção turística através da apropriação simbólica das paisagens do patrimônio cultural. As imagens a seguir demonstram algumas das situações descritas acima.

Figura 10 - Fachada do Mosteiro e Igreja do Carmo, no Centro Histórico de Salvador, BA. A fachada restaurada se integra ao conjunto requalificado do centro histórico, compondo um extenso cenário para o consumo turístico.

Fonte: Skycrapercity. Foto de Fiatbao, 2006. http://www.skyscrapercit y.com/showthread.php?t $=394170$
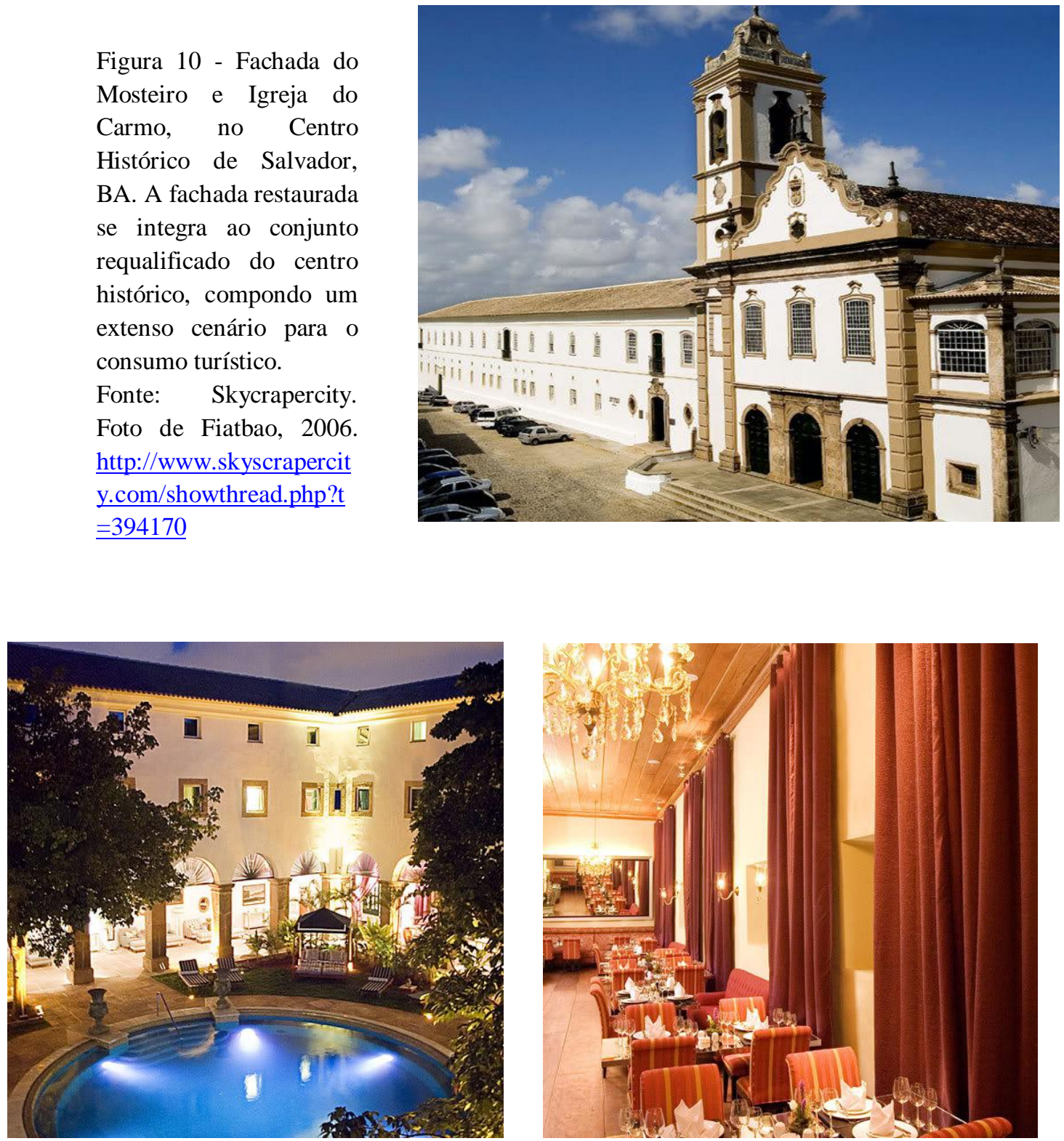

Figuras 11 e 12 - Interior do Convento do Carmo, refuncionalizado como meio de hospedagem 05 estrelas ï o Pestana Convento do Carmo Hotel, da rede portuguesa de hotéis. Observa-se que a introdução de objetos específicos de um equipamento voltado ao turismo, como piscina e restaurante transformam o significado desse importante edifício histórico do Centro Histórico. Fonte: Skycrapercity. Foto de Fiatbao, 2006. http://www.skyscrapercity.com/showthread.php?t=394170 . 
Embora o Programa de Recuperação do Centro Histórico de Salvador tenha apresentado resultados satisfatórios na expectativa de seus idealizadores, em pesquisa realizada anteriormente (Sotratti, 2005), revelamos os efeitos ambíguos e mesmo antagônicos desse Programa. Analisando a sequencia das etapas da implantação da proposta, observamos claramente a importância da paisagem e do cenário recuperado nas prioridades do Programa de Recuperação (SOTRATTI, 2005, pp. 145-151). A paisagem que envolve o largo do Pelourinho tornou-se o epicentro das primeiras intervenções, de forma a fortalecer a imagem do Centro Histórico de Salvador recuperado. No entanto, a área eleita como segunda etapa do Programa reúne, curiosamente, quarteirões localizados relativamente distantes do largo do Pelourinho, mas de alcance visual direto deste. Estes quarteirões reforçam o caráter fachadista da proposta e a importância da paisagem do Centro Histórico recuperada $\ddot{i}$ mesmo que fragmentada - para fortalecimento da imagem do produto turístico Bahia. As Figuras 13 e 14 demonstram esta relação.

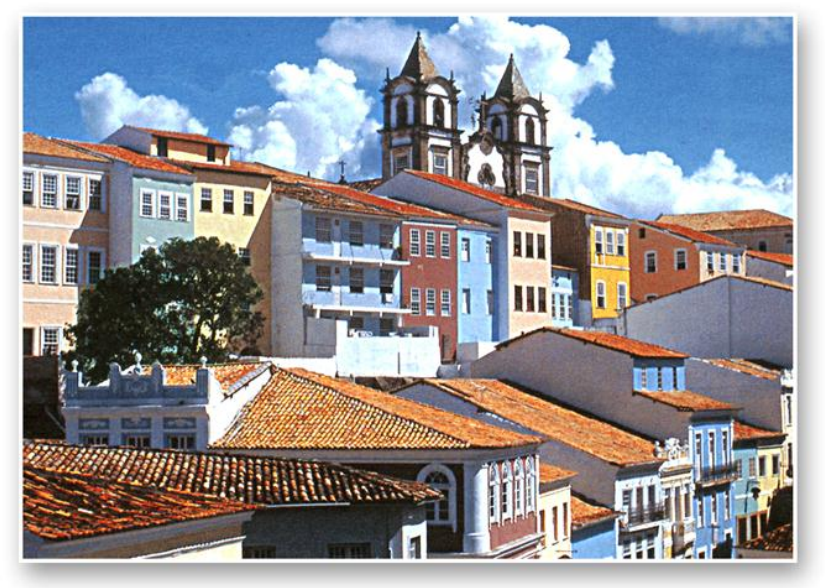

Figura 13 - Paisagem comumente valorizada pela propaganda turística do Pelourinho. Ao fundo, casario recuperado na 2a. etapa do Programa.

Fonte- Castro (2000, p. 205). 
Figura 14 - Vista recente da paisagem apresentada na figura anterior, a partir do olhar de um turista. Observa-se o mau estado de conservação das fachadas dos casarios recuperados pelo Programa.

Fonte - Foto de Galado, 2008. http://www.skyscrapercity.com/sh owthread.php?t=638011.

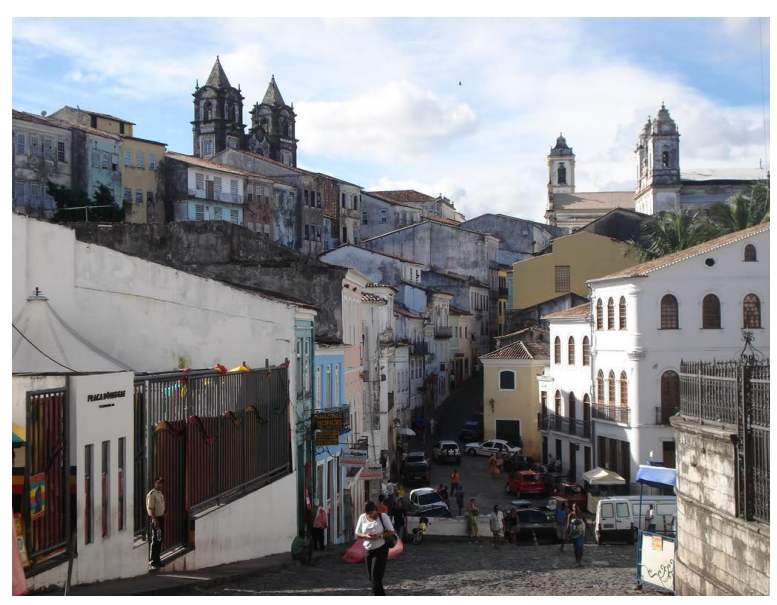

Se analisarmos a Figura 14, podemos perceber os efeitos que a opção fachadista do Programa trouxe à conservação dos edifícios. O alto grau dependência da manutenção das fachadas por parte dos órgãos públicos responsáveis e o pouco envolvimento da iniciativa privada com a conservação do local compromete a paisagem do conjunto arquitetônico que envolve o largo do Pelourinho e fragiliza a imagem de sucesso da requalificação. Curiosamente, este pesquisador teve dificuldade em obter uma imagem recente desse ângulo específico tirada por turistas ou moradores da cidade, talvez em função das más condições de conservação do conjunto.

\section{Considerações Finais}

A análise apresentada neste artigo demonstra a importância da paisagem na produção turística das cidades atuais. A paisagem, por meio de seu conteúdo simbólico e de suas representações, se torna um poderoso elemento da psicosfera, assim como da turistificação e da mercantilização dessas áreas, que expressam nitidamente ideologias espaciais que orientam o processo de apropriação e valorização destas pelo turismo.

Dessa forma, torna-se necessário uma discussão mais minuciosa acerca do papel da paisagem, mais especificamente dos centros históricos turistificados, na legitimação de ideologias espaciais, conforme aponta Berdoulay (1985) em sua discussão sobre a ideologia como fenômeno geográfico. 


\section{Notas}

\footnotetext{
${ }^{1}$ Para mais informações sobre as premissas e conceitos que envolvem a sociedade americana em relação ao marketing e consumo ver: http://www.marketingpower.com.

2 Para mais informações sobre a história, importância simbólica e turística da Torre Eiffel, ver: http://www.tour-eiffel.fr.
}

3.Para mais informações, ver na reportagem íntegra: http://www.cruzeirodosul.inf.br/materia.phl?editoria=40\&id=203887

${ }^{4}$ O Programa de Desenvolvimento do Turismo ï PRODETUR ï consistiu num programa governamental iniciado em 1995 que tinha como objetivo expandir a atividade turística de forma planejada e estratégica nos estados nordestinos e na região norte de Minas Gerais. Contando com recursos do Banco Interamericano de Desenvolvimento $\ddot{~}$ BID, do Banco Nacional de Desenvolvimento $\ddot{~}$ BNDES e do Banco do Nordeste do Brasil $\ddot{i}$ BNB, destinava-se a financiar projetos de infraestrutura como saneamento, sistemas de água e esgoto, transportes e construção e modernização de aeroportos, além de apoio ao desenvolvimento institucional de órgão estaduais e municipais de turismo e preservação do patrimônio histórico e ambiental (GOVERNO FEDERAL/BNDES, 1999). Para mais informações, ver GOVERNO FEDERAL DO BRASIL/BANCO NACIONAL DE DESENVOLVIMENTO. PRODETUR: Infraestrutura e seus Reflexos no Turismo. Disponível em: <http://www.bndes.gov.br/conhecimento/setorial/get4is06.pdf >. Acesso em: 11 jan. 2010.

\section{Referências Bibliográficas}

ALFONSO, Louise Prado. EMBRATUR: Formadora de Imagens da Nação Brasileira. Campinas, SP, 2006, Dissertação (Mestrado em Antropologia Social). Instituto de Filosofia e Ciências Humanas, Universidade Estadual de Campinas ï UNICAMP.

BERDOULAY, Vincent. Les Idéologies comme Phénomènes Géographiques. Cahiers de Géographie du Québec, vol. 29, no. 77, setembro 1985. 
. La Historia de la Geografía en el Desafío de la Prospectiva. Boletín de la A.G.E, no. 51, pp. 09-23, 2009.

BORJA, JORDI. Grandes Projetos Metropolitanos: Mobilidade e Centralidade. In: ASSOCIAÇÃO VIVA O CENTRO. Os Centros das Metrópoles: Reflexões e Propostas para a Cidade Democrática do séc. XXI. São Paulo: Editora Terceiro Nome: Viva o Centro: Imprensa Oficial do Estado, 2001.

CHIAS, Josep. Turismo: O Negócio da Felicidade. São Paulo: Editora SENAC, 2007.

GASTAL, Susana. Turismo: Imagens e Imaginários. São Paulo: Ed. Aleph, 2005.

KOTLER, Philip et al. Marketing de Lugares: Como Conquistar Crescimento de Longo Prazo na América Latina e no Caribe. São Paulo: Prentice Hall, 2006.

LOHMANN, Guilherme \& PANOSSO NETTO, Alexandre. Teoria do Turismo: Conceito, Modelos e Sistemas. São Paulo: Editora Aleph, 2008.

LUCHIARI, Maria Tereza Duarte Paes. A (re)Significação da Paisagem no Período Contemporâneo. In: Corrêa, R. L. \& Rosendahl, Z. (orgs). Paisagem, Imaginário e Espaço. Rio de Janeiro: EdUERJ, pp.10-28, 2001. 
Urbanização turística: um Novo Nexo entre o Lugar e o Mundo. In: SERRANO, Célia, BRUHNS, Heloísa Turini \& LUCHIARI, Maria Tereza Duarte Paes (orgs). Olhares Contemporâneos sobre o Turismo. Campinas, São Paulo: Papirus Editora, pp. 105-130, 2004.

PORTAS, Nuno. Lânterpretazione del Progetto Urbano. Revista Urbanística. Roma:, no.110, giugno, 1998 .

SANTOS, Milton. Técnica, espaço e tempo. Globalização e meio técnico-científico informacional. São Paulo: Hucitec, 1994.

A Natureza do Espaço. Técnica e Tempo. Razão e Emoção. 2 ed. São Paulo: Hucitec, 1997.

. Por uma Geografia Nova: Da Crítica da Geografia a uma Geografia Crítica. São Paulo: EDUSP, 2002.

SASSEN, Saskia e ROOST, Frank. A Cidade: Local Estratégico para a Indústria Global do Entretenimento. Espaço e Debates. São Paulo, ano XVII, n. 41, p. 67-75, 2001.

SILVA, Alexsandro Ferreira Cardoso da \& FERREIRA, Ângela Lúcia de Araújo. Dinâmica Imobiliária e Turismo: Novas Relações, Novos Riscos. Observatório das Metrópoles. Cadernos Metrópole, no.18, 2007, pp. 109-133. 
SILVA, Alexsandro Ferreira Cardoso da et al. Novas Tipologias Habitacionais perante a Expansão do Capital Imobiliário-Turístico em Natal, RN. Observatório das Metrópoles. Cadernos Metrópole, no.16, 2006, pp. 141-162.

SILVEIRA, Maria Laura. Da Fetichização dos Lugares à Produção Local do Turismo. In: RODRIGUES, Adyr Balastreri. Turismo, Modernidade, Globalização. $3^{\mathrm{a}}$. Edição.São Paulo: Hucitec, 2002.

SOTRATTI, Marcelo Antonio. Pelas Ladeiras do Pelô: A Requalificação urbana Como Afirmação de um Produto Turístico. Campinas, SP, 2005, Dissertação (Mestrado em Geografia). Instituto de Geociências, Universidade Estadual de Campinas ï UNICAMP.

Enviado para publicação em dezembro de 2011.

Aceito para publicação em dezembro de 2011. 